\title{
Ruthenium Carbene Mediated Metathesis of Oleate-Type Fatty Compounds
}

\author{
Bassie B. Marvey ${ }^{1, *}$, Constance K. Segakweng ${ }^{1}$ and Manie H. C. Vosloo ${ }^{2}$ \\ 1 Department of Chemistry, North-West University, P/Bag X2046, Mafikeng, 2735, South Africa \\ 2 School of Chemistry, North-West University, P/Bag X6001, Potchefstroom, South Africa \\ *Author to whom correspondence should be addressed; Tel. +27-18-389 2527; Fax: +27 18389 2052; \\ E-mails: bassie.marvey@nwu.ac.za; cksegakweng@webmail.co.za; manie.vosloo@nwu.ac.za
}

Received: 16 November 2007; in revised form: 28 March 2008 / Accepted: 17 April 2008 /

Published: 18 April 2008

\begin{abstract}
The complexes $\mathrm{RuCl}_{2}\left(\mathrm{PCy}_{3}\right)_{2}(=\mathrm{CHPh}), \mathbf{1}$, and $\mathrm{RuCl}_{2}\left(\mathrm{PCy}_{3}\right)\left(\mathrm{H}_{2} \mathrm{IMes}\right)(=\mathrm{CHPh})$, 2, proved to be active catalysts for the self-metathesis of oleate-type fatty compounds containing the ester, hydroxyl, epoxy and carboxylic acid functional groups. At elevated reaction temperatures $\mathbf{2}$ showed a higher activity, stability and lower selectivity for primary metathesis products compared to $\mathbf{1}$. A profound influence of organic functional groups on catalyst activity and selectivity was found and from relative activities and selectivities 2 has proved to be more resistant to deactivation by polar functional groups and more inclined to promote double bond isomerisation than $\mathbf{1}$. The observed catalyst deactivation by oxygen-containing functional groups could be attributed to a phosphine displacement side reaction.
\end{abstract}

Keywords: Olefin Metathesis, Grubbs catalysts, oleate-type fatty compounds

\section{Introduction}

The self- and cross-metathesis of olefinic fatty acids and esters is an elegant way for the production of high value intermediates with interesting applications in the polymer, pharmaceutical and petrochemical industries [1-4]. At Dow Chemical Company [5] seed oils are being explored for a number of applications inter alia epoxy thermoplastics and thermosets, polyurethane foams, thermoplastic polyurethanes, polyolefin comonomers and surfactants. The utilization of plant oils and derivatives in end applications or as ingredients for product formulations has recently attracted much attention due to their renewable supply, low cost, versatility and their green chemistry. Scheme 1 
illustrates the various routes to industrial end-products from plant oils to high value intermediates and end-products using olefin metathesis reaction.

To carry out some of these transformations the well-defined Grubbs precatalysts are a logical choice due to their relatively high tolerance for polar organic functional groups compared to the classical ill-defined metathesis catalysts [6-9]. Buchowicz and Mol [10] demonstrated that reaction rates for the self-metathesis of fatty acid esters with the Grubbs first generation catalyst $\mathrm{RuCl}_{2}\left(\mathrm{PCy}_{3}\right)_{2}(=\mathrm{CHPh})(\mathbf{1})$ were comparable to that of unsubstituted olefins. Warwel et al. [11] used 1 for converting linear olefinic esters to $\alpha$-olefins and $\alpha$-unsaturated esters by ethenolysis. The $\omega$ unsaturated esters were subsequently converted to highly branched polyolefins and to difunctionalised fatty acid methyl esters for the synthesis of functionalised polyethers and unsaturated polyesters.

Scheme 1. Routes to industrial end-products via olefin metathesis reaction [1,5,11].

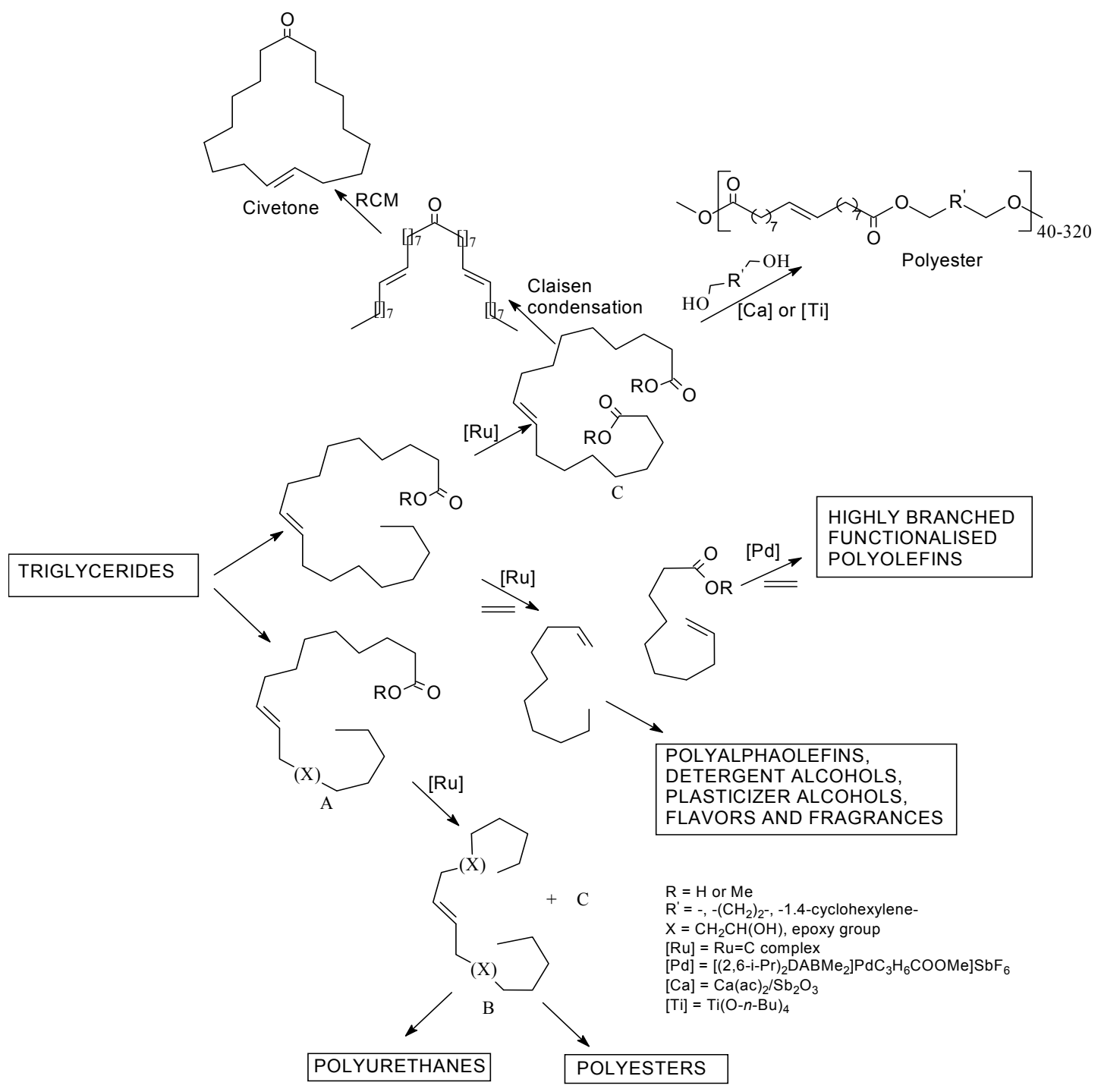

This study explores the self-metathesis of oleate-type fatty compounds, namely, methyl oleate (MO), methyl 12-hydroxyoleate (MHO), methyl 12,13-epoxyoleate (MEO) and oleic acid (OA), and compares the metathesis activities and selectivities of the well-defined first- and second generation Grubbs precatalysts $\mathbf{1}$ and 2, respectively, on these substrates. Although these compounds have 
potential in the formulation of high value products, very little is reported in the literature on their applications based on the metathesis reaction. It is envisaged that the results obtained in this study would broaden our understanding of their metathetical chemistry and of the influence of different polar functional groups on the catalytic performance of Ru-based metathesis catalysts.
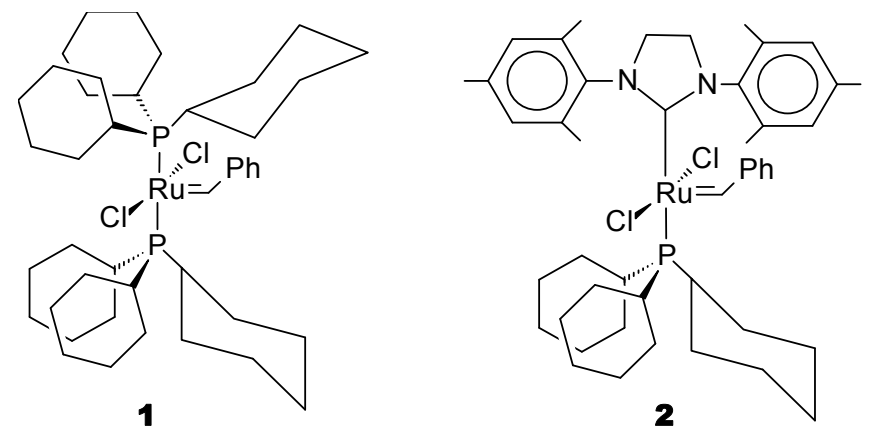

\section{Experimental}

\subsection{Materials and Apparatus}

Chlorobenzene $(\mathrm{PhCl})$ dichloromethane $(\mathrm{DCM})$, 1,2-dichloroethane $(\mathrm{DCE})$, benzene $(\mathrm{PhH}), n$ hexane (Hex) were all reagent grade from Sigma-Aldrich. Ethyl vinyl ether was purchased from Fluka. Methyl oleate ( $\geq 99 \%$ ), methyl 12-hydroxyoleate (99\%), methyl 12,13-epoxyoleate ( $\geq 99 \%)$ and oleic acid (65-88\%) were obtained from Sigma-Aldrich and were all treated with activated alumina and stored under $\mathrm{N}_{2}$ at a subzero temperature. Grubbs precatalysts $\mathbf{1}$ and $\mathbf{2}$ were stored under $\mathrm{N}_{2}$ and used as purchased from Sigma-Aldrich. Chromatograms were obtained using Varian Star $3400 C X$ GC equipped with a DB-624 capillary column (J\&W Scienctific, $30 \mathrm{~m} \times 0.53 \mathrm{~mm}$ ) and a flame ionisation detector (FID). The oven temperature was held at $150{ }^{\circ} \mathrm{C}$ for $0.1 \mathrm{~min}$ and then increased to $260{ }^{\circ} \mathrm{C}$ at a rate of $15^{\circ} \mathrm{C} \mathrm{min}^{-1}$. The injector temperature was set at $270{ }^{\circ} \mathrm{C}$ and the detector temperature at $300{ }^{\circ} \mathrm{C}$ with $\mathrm{N}_{2}$ as carrier gas. The mass spectra were measured on a Varian Saturn 4D gas chromatographmass spectrometer (GC-MS) with a Varian Star $3400 C X$ GC equipped with a WCOT fused silica J\&W DB-5 column (30 m x 25mm; film thickness $0.25 \mu \mathrm{m})$.

\subsection{Metathesis experiments}

All manipulations were performed using standard Schlenk techniques under $\mathrm{N}_{2}$ atmosphere. In a typical experiment $16.4 \mathrm{mg}$ of $1(0.02 \mathrm{mmol})$ or $6.3 \mathrm{mg}$ of $2(0.0074 \mathrm{mmol})$ was dissolved in $2.0 \mathrm{~mL}$ of the solvent followed by the addition of $2.0 \mathrm{mmol}$ substrate for $\mathbf{1}$ or $0.74 \mathrm{mmol}$ for $\mathbf{2}$ in a glass reactor fitted with a thermometer and a rubber septum. Samples were withdrawn by a syringe at regular time intervals, quenched by the addition of a few drops of ethyl vinyl ether [10], and analysed by GC-FID. Substrate conversions were calculated as $\left(1-\mathrm{C}_{\mathrm{s}}\right) / \Sigma \mathrm{C}_{\mathrm{i}}$ from the corrected peak areas of the GC analyses $[12,13]$. Selectivity towards primary metathesis products (PMP) was calculated using the formula: $\% \mathrm{PMP} / \Sigma(\% \mathrm{PMP}, \% \mathrm{SMP}) \times 100$, where SMP = secondary metathesis products. Product characterisation was done using GC-MS in the electron impact (EI) mode and by spiking with authentic samples. 


\section{Results and Discussion}

\subsection{Optimisation of reaction conditions}

The optimum reaction conditions for Grubbs precatalysts $\mathbf{1}$ and $\mathbf{2}$ were determined using methyl oleate as the model substrate and were subsequently applied on all substrates except where otherwise indicated. The parameters in the optimisation of the Grubbs pre-catalysts were (1) solvent polarity (2) reaction temperature (3) reaction atmosphere and (4) substrate: $\mathrm{Ru}$ molar ratio. Scheme 2 illustrates the formation of the primary metathesis products (PMP), B and $\mathbf{C}$, from the self-metathesis of the oleatetype fatty compounds.

To investigate the influence of solvent polarity on catalyst activity the solvents $\mathrm{Hex}, \mathrm{PhH}, \mathrm{PhCl}$, DCM and DCE were used, having polarities of 9, 11.1, 18.8, 30.9 and 32.7, respectively, according to the Reichardt's normalised solvent polarity scale $\left(E_{\mathrm{T}}^{\mathrm{N}}\right)$ [14]. Figure 1 shows the influence of solvent polarity on catalyst activity expressed as \% conversion with $\mathrm{MO} / \mathrm{Ru}$ molar ratio of 100 . The highest activity was obtained in DCM or DCE both of which have moderate polarities relative to Hex, the solvent of lowest polarity. The poor solubility of precatalysts in acetone, ethanol, methanol and water, which have relatively higher polarities, was a limitation that led to the exclusion of these solvents in further experiments. The activity of $\mathbf{1}$ increased with increasing solvent polarity in the order Hex < $\mathrm{PhH}<\mathrm{PhCl}<\mathrm{DCM} \sim \mathrm{DCE}$. The observed order of activity showed a positive correlation between solvent polarity and catalyst activity with halogenated solvents (DCM and DCE) providing the best reaction conditions.

Scheme 2. Formation of PMP (B and $\mathbf{C})$ from self-metathesis of $\mathbf{A}$.

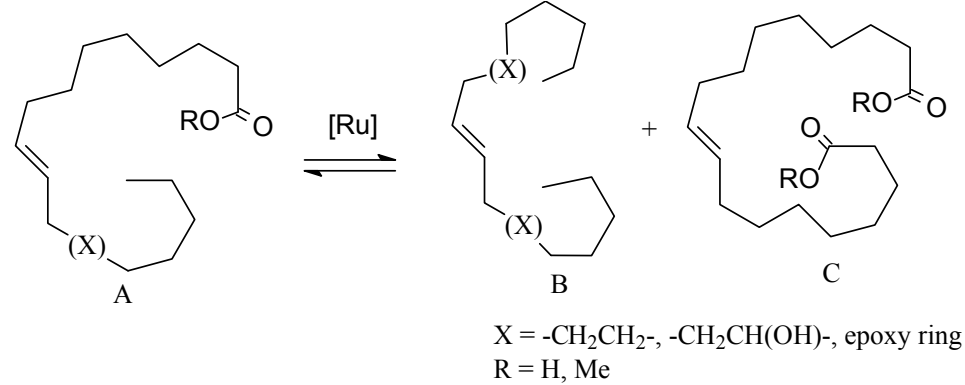

From varying the reaction temperature, the activity of 1 showed no significant change over the temperature range $20-60^{\circ} \mathrm{C}$. However, a sharp increase in activity was observed at $80{ }^{\circ} \mathrm{C}$ along with the formation of secondary metathesis products (SMP) resulting from double bond isomerisation. A further increase in reaction temperature led to a decrease in catalyst activity. Figure 2 illustrates the influence of reaction temperature on the activity and selectivity of the precatalysts $\mathbf{1}$ and $\mathbf{2}$ and Scheme 3 shows possible SMP (F-J) from the cross-metathesis of the substrate olefin A with isomerisation products $\mathbf{D}$ and $\mathbf{E}$.

Under air atmosphere a slightly lower activity was observed with MO conversion of $46.7 \%$ compared to $49 \%$ under $\mathrm{N}_{2}$. The deactivation of 1 under air atmosphere was nevertheless insignificant compared with the extent to which the ill-defined metathesis catalysts deactivate under similar conditions [7].

A steady increase in the turnover number (TON) was observed for $\mathrm{MO} / \mathbf{1}$ molar ratios from 100 to 1000. Thereafter a sharp decrease in the TON occurred (Table 1) after reaching a maximum of 525 at a 
$\mathrm{MO} / \mathbf{1}$ molar ratio of 1000 with a selectivity of $100 \%$. Generally the optimum conditions obtained for 1 using MO compared favourably with those previously obtained by Buchowicz and Mol [10].

Figure 1. Influence of solvent polarity on $\mathrm{MO}$ conversion with $\mathrm{MO} / \mathrm{Ru}$ molar ratio of 100 at $20{ }^{\circ} \mathrm{C}$ after $4 \mathrm{~h} .(\circ \mathbf{1}, \square \mathbf{2})$.

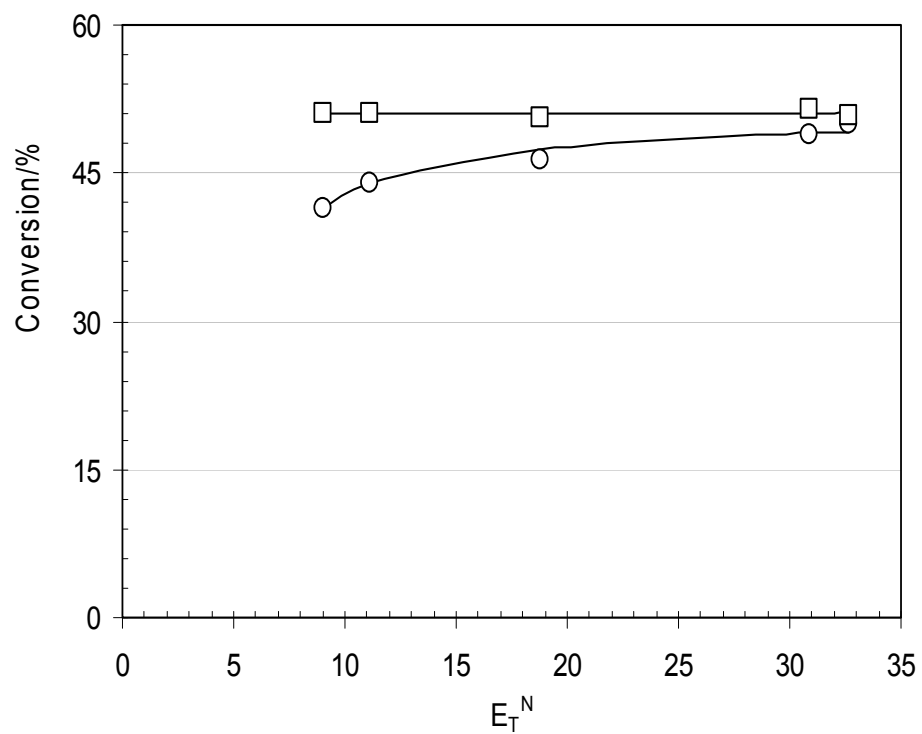

Scheme 3. SMP from cross metathesis of $\mathbf{A}$ with isomerisation products $\mathbf{D}$ and $\mathbf{E}$.

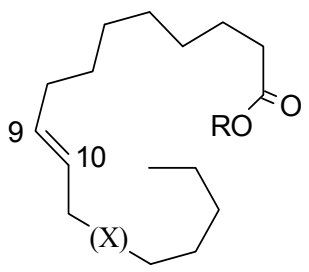

A

1 isomerisation<smiles>[R20]C(=O)CCCCCCCCC=COCCCCC</smiles><smiles>[R20]C(=O)CCCCCC/C=C\CCOCCCCCC</smiles>

F (self-metathesis of D)

$\mathbf{G}$ (self-metathesis of $\mathrm{E}$ )

H (cross-metathesis of A with D)

I (cross-metathesis of A with E)

$\mathbf{J}$ (cross-metathesis of $\mathrm{D}$ with $\mathrm{E}$ )

Secondary metathesis products (SMP)

When $\mathrm{MO}$ underwent self-metathesis in the presence of $\mathbf{2}$, solvent polarity had very little influence on catalyst activity, in contrast to the results obtained with 1. From Figure 1 we see no significant difference in catalyst activity with the change in solvent polarity. 
From varying the reaction temperature, the activity of $\mathbf{2}$ showed no significant change within the temperature range $20-60{ }^{\circ} \mathrm{C}$ but then a sharp increase in activity occurred at $80{ }^{\circ} \mathrm{C}$ and beyond with the formation of SMP. Catalyst 2 showed stability even at $120{ }^{\circ} \mathrm{C}$ whereas 1 showed some deactivation at $100{ }^{\circ} \mathrm{C}$ already. However, a comparatively low selectivity for PMP at elevated reaction temperatures implied that the reaction conditions were strongly acting in favour of double bond isomerisation. Figure 2 compares the activities and selectivities of $\mathbf{1}$ and $\mathbf{2}$ on MO self-metathesis. It can be seen from the results obtained that the activity and selectivity towards the PMP in both cases was only comparable within the temperature range $20-60{ }^{\circ} \mathrm{C}$.

A slightly lower MO conversion (50.5\%) was obtained in air compared to $51.5 \%$ under $\mathrm{N}_{2}$ atmosphere. A steady increase in TON up to a maximum of 675 corresponding to $\mathrm{MO} / 2$ molar ratio of 1500 was observed (Table 1). The observed decrease in TON after reaching maximum MO loading for both 1 and 2 was consistent with the results obtained by Jordaan and Vosloo [15] using a Ru catalyst with a chelating pyridinyl-alcoholato ligand.

Figure 2. Influence of reaction temperature on MO conversion and PMP selectivity with $\mathrm{MO} / \mathrm{Ru}$ molar ratio of 100 after $4 \mathrm{~h}$ in DCM. (Conversion: $\diamond \mathbf{1}, \Delta \mathbf{2}$; Selectivity: $\bigcirc \mathbf{1}, \square \mathbf{2}$ ).

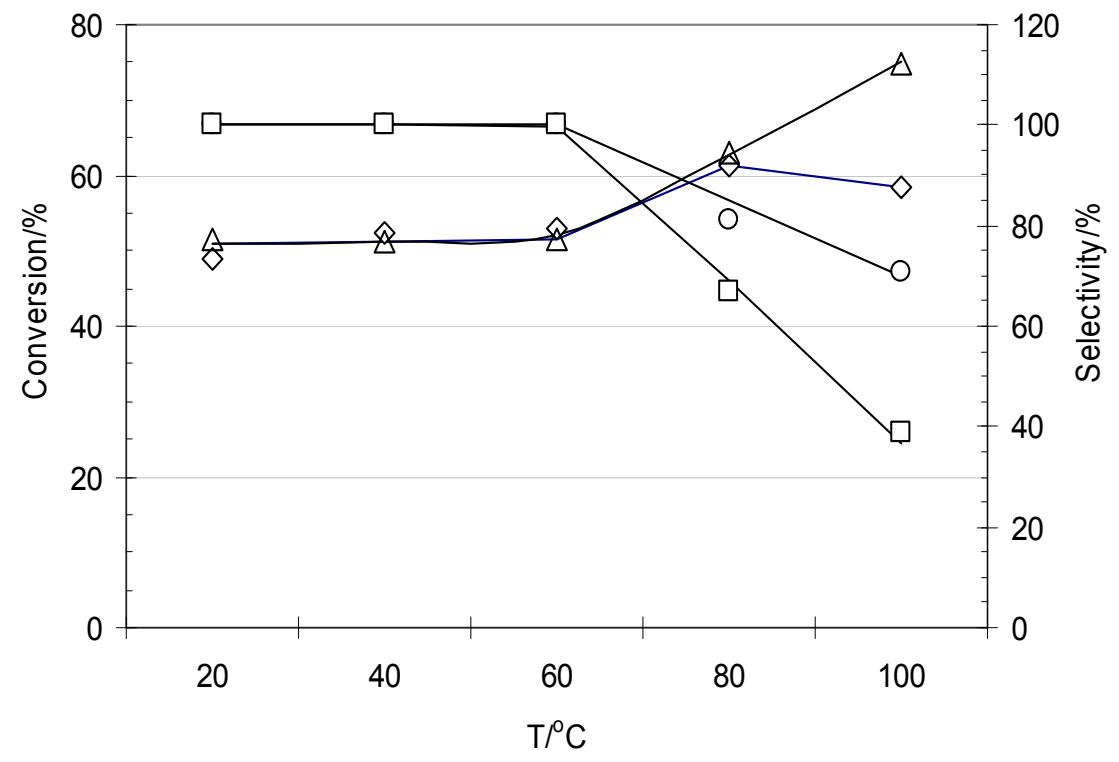

Table 1. Self-metathesis of MO in the presence of 1 and 2 in DCM at $20^{\circ} \mathrm{C}$ after $4 \mathrm{~h}$.

\begin{tabular}{cccccc}
\hline Entry & $\begin{array}{c}\text { MO/Ru } \\
\text { ratio }\end{array}$ & Catalyst $^{\text {Conv }}{ }^{[\mathbf{a}]}$ & $\begin{array}{c}\text { Sel }^{[\mathbf{b}]} \\
\mathbf{( \% )}\end{array}$ & TON $^{[\mathbf{c}]}$ \\
\hline 1 & 100 & $\mathbf{1}$ & 49 & 100 & 49 \\
& & $\mathbf{2}$ & 51.5 & 100 & 51.5 \\
2 & 500 & $\mathbf{1}$ & 50.8 & 100 & 254 \\
& & $\mathbf{2}$ & 51.8 & 100 & 259 \\
3 & 1000 & $\mathbf{1}$ & 52.5 & 100 & 525 \\
& & $\mathbf{2}$ & 51.5 & 100 & 515 \\
4 & 1500 & $\mathbf{1}$ & 29 & 100 & 435 \\
& & $\mathbf{2}$ & 45 & 100 & 675 \\
5 & 2000 & $\mathbf{1}$ & 12.2 & 100 & 244 \\
& & $\mathbf{2}$ & 33 & 100 & 660 \\
\hline
\end{tabular}

${ }^{\text {[a] }}$ Molar \% substrate converted

${ }^{[b]}$ Selectivity towards PMP

[c] $(\mathrm{MO} / \mathrm{Ru})$ (Conv) 


\subsection{Influence of oxygen containing functional groups on catalyst activity and selectivity}

The metathesis activity and selectivity of $\mathbf{1}$ and $\mathbf{2}$ were examined using MO, MHO, MEO and OA as substrates with substrate/Ru molar ratio of 100 and DCM as solvent. The influence of the different organic functional groups on catalyst activity and selectivity is discussed in this section.

\subsubsection{Influence of oxygen containing functional groups on the activity and selectivity of 1}

The products and the yields obtained from the metathesis of $\mathrm{MO}, \mathrm{MHO}, \mathrm{MEO}$ and $\mathrm{OA}$ in the presence of $\mathbf{1}$ are given in Table 2. The typical gas chromatograms of reaction mixtures under typical reaction conditions of these fatty compounds are given in Figure 3. For MO and MHO a close to 2:1:1 statistical product distribution was attained at steady state with conversions of 49 and $39.6 \%$ respectively and a selectivity of $>99 \%$ towards PMP. The MO conversion was slightly higher than that reported in the literature [10] under similar conditions. MHO conversion was, on the other hand, comparable to the reported conversions for MO and methyl erucate. In the case of MEO and OA, conversions of 23.5 and $24.5 \%$ were obtained with selectivities of 57 and $88 \%$ respectively. The presence of SMP in the MEO and OA product streams suggested the occurrence of double bond isomerisation in the presence of $\mathbf{1}$. Table 3 compares substrate conversions, selectivities and the yields obtained for PMP and SMP. The decreasing order of substrate reactivity was $\mathrm{MO}>\mathrm{MHO}>\mathrm{OA}>$ MEO, thus indicating that $\mathbf{1}$ is less tolerant towards the epoxy and the carboxylic acid groups compared to the hydroxyl and the ester groups. The lower reactivity of $\mathbf{1}$ in the presence of MHO, OA and MEO seems to suggest phosphine displacement by oxygen-bearing nucleophiles, a side reaction competing with dissociative substitution of a phosphine ligand with an olefinic substrate [9], to form four coordinate $\mathrm{Ru}(\mathrm{OR})_{2} \mathrm{~L}(=\mathrm{CHPh})$ complexes in accordance to the route proposed by Coalter et al. [16]. In addition, a $\beta$-hydride elimination reaction occurs in which the metallocycle intermediate once formed gives the allyl hydride intermediate which finally forms a coordinated alkene [17].

Figure 3. Typical GC's of the metathesis products of (A) MO (B) MHO (C) MEO and (D) $\mathrm{OA}$ in the presence of $\mathbf{1}$ or $\mathbf{2}$ at $20^{\circ} \mathrm{C}$. Peak numbers correspond to entries in Table 2.

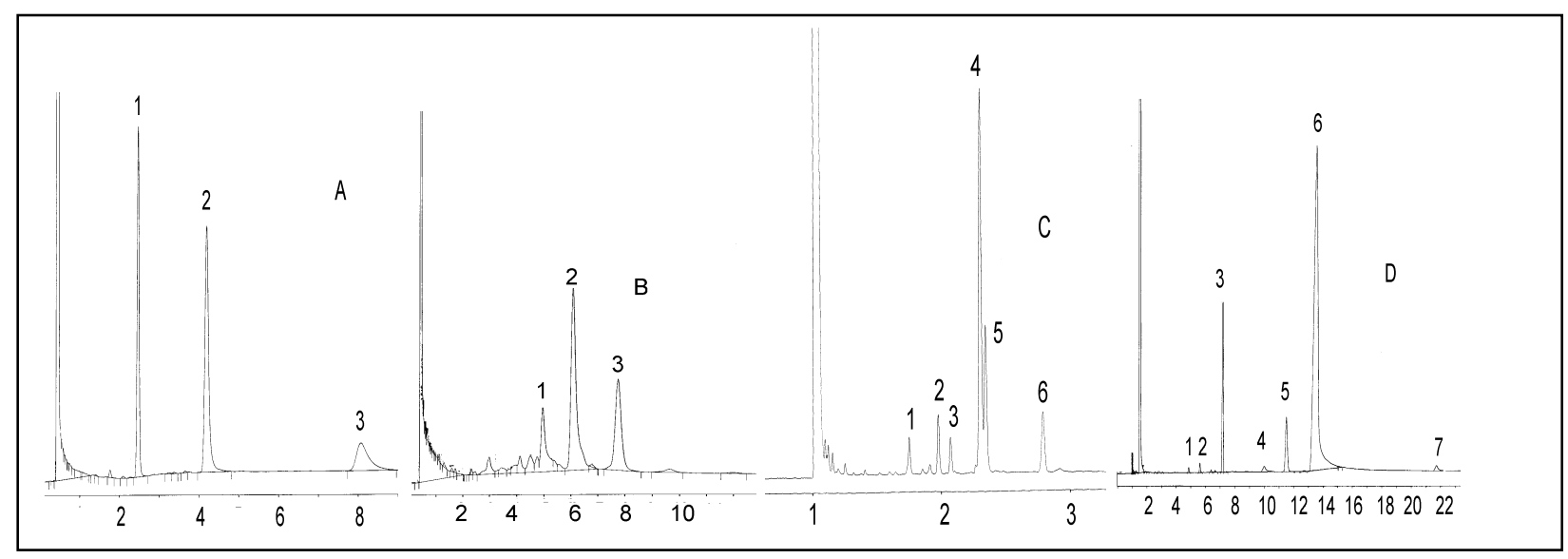

Retention time/min 
Table 2. Products and yields resulting from the metathesis of oleate-type fatty compounds in DCM at $20^{\circ} \mathrm{C}$ after $4 \mathrm{~h}$.

\begin{tabular}{|c|c|c|c|c|c|}
\hline Entry ${ }^{\text {[a] }}$ & Product Name & Formula $^{[b]}$ & $\mathbf{m} / \mathbf{e}$ & Yiel & $(\%)$ \\
\hline A & $\underline{\mathrm{MO}}$ & & & $\underline{1}$ & $\underline{\mathbf{2}}$ \\
\hline 1 & 9-Octadecene $\mathrm{e}^{[\mathrm{c}]}$ & $\mathrm{C}_{9}=\mathrm{C}_{9}$ & 252 & 24.5 & 26.3 \\
\hline 2 & Methyl oleate & $\mathrm{C}_{9}=\mathrm{C}_{8} \mathrm{COOC}$ & 296 & 51.0 & 48.5 \\
\hline 3 & Dimethyl 9-octadecenedioate ${ }^{[\mathrm{c}]}$ & $\mathrm{COOCC}_{8}=\mathrm{C}_{8} \mathrm{COOC}$ & 340 & 24.5 & 25.2 \\
\hline B & $\underline{\mathrm{MHO}}$ & & & & \\
\hline 1 & 9-Octadecene-7,12-diol ${ }^{[\mathrm{c}]}$ & $\mathrm{C}_{9}(\mathrm{OH})=\mathrm{C}_{9}(\mathrm{OH})$ & 284 & 6.6 & 20.1 \\
\hline 2 & Methyl 12-hydroxyoleate & $\mathrm{C}_{9}(\mathrm{OH})=\mathrm{C}_{8} \mathrm{COOC}$ & 312 & 60.4 & 51.6 \\
\hline 3 & Dimethyl 9-octadecenedioate $^{[\mathrm{c}]}$ & $\mathrm{COOCC}_{8}=\mathrm{C}_{8} \mathrm{COOC}$ & 340 & 33.0 & 28.3 \\
\hline $\mathrm{C}$ & $\underline{\mathrm{MEO}}$ & & & & \\
\hline 1 & 6,7,12,13-Diepoxy-9-octadecene ${ }^{[\mathrm{c}]}$ & $\mathrm{C}_{5}(\mathrm{COC}) \mathrm{C}_{2}=\mathrm{C}_{2}(\mathrm{COC}) \mathrm{C}_{5}$ & 280 & 0.8 & 8.1 \\
\hline 2 & Methyl 10,11-epoxy-7-hexadecenoate ${ }^{[\mathrm{d}]}$ & $\mathrm{COOCC}_{6}=\mathrm{C}_{2}(\mathrm{COC}) \mathrm{C}_{5}$ & 282 & 4.1 & 24.4 \\
\hline 3 & Dimethyl 7-hexadecenedioate $^{[\mathrm{d}]}$ & $\mathrm{COOCC}_{6}=\mathrm{C}_{8} \mathrm{COOC}$ & 312 & 5.9 & 0.1 \\
\hline 4 & Methyl 12,13-epoxyoleate & $\mathrm{COOCC}_{8}=\mathrm{C}_{2}(\mathrm{COC}) \mathrm{C}_{5}$ & 310 & 76.5 & 42.0 \\
\hline 5 & Dimethyl 9-octadecenedioate ${ }^{[c]}$ & $\mathrm{COOCC}_{8}=\mathrm{C}_{8} \mathrm{COOC}$ & 340 & 12.7 & 25.4 \\
\hline $\mathrm{D}$ & $\underline{\mathrm{OA}}$ & & & & \\
\hline 1 & 7-Tetradecene $\mathrm{e}^{[\mathrm{d}]}$ & $\mathrm{C}_{7}=\mathrm{C}_{7}$ & 196 & - & 10.9 \\
\hline 2 & 7-Pentadecene ${ }^{[\mathrm{d}]}$ & $\mathrm{C}_{7}=\mathrm{C}_{8}$ & 210 & - & 11.1 \\
\hline 3 & 8 -Hexadecene ${ }^{[\mathrm{d}]}$ & $\mathrm{C}_{8}=\mathrm{C}_{8}$ & 224 & 3 & 30.6 \\
\hline 4 & 8 -Heptadecene ${ }^{[\mathrm{d}]}$ & $\mathrm{C}_{8}=\mathrm{C}_{9}$ & 238 & - & 4.3 \\
\hline 5 & $9-$ Octadecene $e^{[\mathrm{c}]}$ & $\mathrm{C}_{9}=\mathrm{C}_{9}$ & 252 & 21.1 & 9.0 \\
\hline 6 & Oleic acid & $\mathrm{C}_{9}=\mathrm{C}_{8} \mathrm{COOH}$ & 282 & 75.5 & 33.1 \\
\hline 7 & 9-Octadecenedioic acid ${ }^{[\mathrm{c}]}$ & $\mathrm{HOOCC}_{8}=\mathrm{C}_{8} \mathrm{COOH}$ & 312 & 0.4 & 1.0 \\
\hline
\end{tabular}

\footnotetext{
${ }^{\text {[a] }}$ Numbers correspond to peak numbers in Figure 3A-D

${ }^{[b]}$ Hydrogens omitted for simplicity

${ }^{[c]}$ PMP resulting from the self-metathesis of substrate esters

${ }^{\text {[d] }}$ SMP resulting from the cross-metathesis of isomerisation products
}

\subsubsection{Influence of oxygen containing functional groups on the activity and selectivity of 2}

Table 2 shows the products and yields obtained from the self-metathesis of MO, MHO, MEO and OA in the presence of 2 . The selectivity towards the PMP was $>99 \%$ for MO and MHO metathesis with conversions of 51.5 and $48.4 \%$ respectively. On the other hand MEO and OA metathesis gave conversions of 58 and $67 \%$, respectively, accompanied by higher isomerisation activity judging from the high SMP yields obtained in this instance. Table 4 compares substrate conversions, selectivities and the yields obtained for PMP and SMP. The observed substrate reactivity in decreasing order was 
$\mathrm{OA}>\mathrm{MEO}>\mathrm{MO}>\mathrm{MHO}$, thus indicating that the tolerance of complex 2 towards the epoxy and the carboxylic acid groups is much higher compared to that of complex $\mathbf{1}$. These results further indicate that polar organic functional groups possess a significant influence on both substrate reactivity and catalyst selectivity. Indeed 2 showed an improved activity with double bond isomerisation more pronounced than was the case with $\mathbf{1}$. The higher activity of $\mathbf{2}$ had been attributed to the stabilisation of the intermediate metallacycle by the more bulky and basic $N$-heterocyclic carbene ligand [6,8-9,1819]. Indeed the results obtained with and $\mathbf{1}$ and $\mathbf{2}$ served to further demonstrate that these catalysts are highly resistant to deactivation by olefins containing polar functional groups compared to the illdefined metathesis catalysts [20].

Table 3. Activity and selectivity of $\mathbf{1}$ on oleate-type fatty compounds with substrate/1 molar ratio of 100 in DCM after $4 \mathrm{~h}$.

\begin{tabular}{cccccc}
\hline Substrate & $\mathbf{T e m p}^{\left({ }^{\mathbf{C}} \mathbf{C}\right)}$ & $\begin{array}{c}\mathbf{P M P}^{[\mathbf{a}]} \\
(\mathbf{\%})\end{array}$ & $\begin{array}{c}\mathbf{S M P}^{[\mathbf{b}]} \\
(\mathbf{\%})\end{array}$ & $\begin{array}{c}\mathbf{C o n v}^{[\mathbf{c}]} \\
(\mathbf{\%})\end{array}$ & $\begin{array}{c}\mathbf{S e l}^{[\mathbf{d}]} \\
(\mathbf{\%})\end{array}$ \\
\hline MO & 20 & 49.0 & - & 49.0 & 100 \\
MO & 100 & 41.5 & 17 & 58.5 & 71.0 \\
MHO & 20 & 39.6 & - & 39.6 & 100 \\
MEO & 20 & 13.5 & 10.0 & 23.5 & 57.4 \\
OA & 20 & 21.5 & 3.0 & 24.5 & 87.8 \\
\hline
\end{tabular}

${ }^{\text {[a] }}$ Primary metathesis products resulting from the self-metathesis of substrate esters

${ }^{[b]}$ Secondary metathesis products resulting from the cross-metathesis of isomerisation products

${ }^{[c]}$ Molar \% substrate converted

${ }^{\text {[d] }}$ Selectivity towards PMP

Table 4. Activity and selectivity of $\mathbf{2}$ on oleate-type fatty compounds with substrate/2 molar ratio of 100 in DCM after $4 \mathrm{~h}$.

\begin{tabular}{cccccc}
\hline Substrate & $\left.\operatorname{Temp}^{\mathbf{0}} \mathbf{C}\right)$ & $\begin{array}{c}\mathbf{P M P}^{[\mathbf{a}]} \\
\mathbf{( \% )}\end{array}$ & $\begin{array}{c}\mathbf{S M P}^{[\mathbf{b}]} \\
\mathbf{( \% )}\end{array}$ & $\begin{array}{c}\mathbf{C o n v}^{[\mathbf{c}]} \\
\mathbf{( \% )}\end{array}$ & $\begin{array}{c}\text { Sel }^{[\mathbf{d}]} \\
(\mathbf{\%})\end{array}$ \\
\hline MO & 20 & 51.5 & - & 51.5 & 100 \\
MO & 120 & 22.0 & 59.0 & 81.0 & 27.2 \\
MHO & 20 & 48.4 & - & 48.4 & 100 \\
MEO & 20 & 33.5 & 24.5 & 58.0 & 57.8 \\
OA & 20 & 10.0 & 56.9 & 66.9 & 14.9 \\
\hline
\end{tabular}

${ }^{\text {[a] }}$ Primary metathesis products resulting from self-metathesis of substrate esters

${ }^{[b]}$ Secondary metathesis products resulting from cross-metathesis of isomerisation products

${ }^{[\mathrm{c}]}$ Molar \% substrate converted

[d] Selectivity towards PMP

\section{Conclusions}

The $\mathrm{Ru}$ complexes $\mathbf{1}$ and $\mathbf{2}$ proved to be active for the self-metathesis of oleate-type fatty compounds. At elevated reaction temperatures $\mathbf{2}$ shows a higher activity, stability and a lesser selectivity towards PMP compared to 1. Furthermore a profound influence of different functional groups on catalyst activity and selectivity was found. In the presence of $\mathbf{1}$ the metathesis reactivity of 
olefinic fatty compounds decreases in the order methyl oleate $>$ methyl 12-hydroxyoleate $>$ oleic acid $>$ methyl 12,13-epoxyoleate whilst with $\mathbf{2}$ the reactivity decreases in the order oleic acid $>$ methyl 12,13-epoxyoleate $>$ methyl oleate $>$ methyl 12-hydroxyoleate; thus indicating from relative conversions that $\mathbf{2}$ is more resistant to deactivation by polar functional groups than $\mathbf{1}$. Indeed $\mathbf{2}$ shows an improved activity, a remarkable tolerance for polar functional groups and a more pronounced double bond isomerisation activity. The relatively low reactivity of $\mathbf{1}$ in the presence of polar functional groups advocates for a phosphine displacement by oxygen-bearing nucleophiles; a side reaction competing with the initiation step and which occurs by dissociative substitution of a phosphine ligand with an olefinic substrate.

\section{Acknowledgements}

The authors wish to thank Dr Johan Jordaan for MS data acquisition and the National Research Foundation of South Africa (NRF) for financial assistance and bursary towards the studies of CKS.

\section{References and Notes}

1. Mol, J.C. Applications of olefin metathesis in oleochemistry: an example of green chemistry. Green Chemistry 2002, 4, 5-13.

2. Mol, J.C. Catalytic metathesis of unsaturated fatty acid esters and oils:catalytic conversion of renewables. Topics in Catalysis 2004, 27, 97-104.

3. Plugge, M.F.C; Mol, J.C. A new synthesis of civetone. Synlett 1991, 507-508.

4. Ivin, K.J. Some recent applications of the olefin metathesis in organic synthesis: A review. J. Mol. Catal. A:Chem. 1998, 133, 1-16.

5. Burdett K.A.; Harris L.D.; Margl P.; Maghon B.R.; Mokhtar-Zadeh T.; Saucier P.C.; Wasserman E.P. Renewable monomer feedstocks via olefin metathesis: fundamental mechanistic studies of methyl oleate ethenolysis with the first generation Grubbs catalyst. Organometallics 2003, 23(9), 2027- 2047.

6. Grubbs, R.H.; Chang, S. Recent advances in olefin metathesis and its applications in organic synthesis. Tetrahedron 1998, 54, 4413-4450.

7. Grubbs, R.H. Olefin metathesis. Tetrahedron 2004, 60, 7117-7140.

8. Sanford, M.S.; Ulman M.; Grubbs, R.H. New insights into the mechanism of Ruthenium-catalyzed olefin metathesis reactions. J. Am. Chem. Soc. 2001, 123, 749-750.

9. Sanford, M.S.; Love, J.A.; Grubbs, R.H. Mechanism and acivity of the Ruthenium olefin metathesis catalysts. J. Am. Chem. Soc. 2001, 123, 65430-6554.

10. Buchowicz, W.; Mol, J. Catalytic activity and selectivity of $\mathrm{Ru}(=\mathrm{CHPh}) \mathrm{Cl}_{2}\left(\mathrm{PCy}_{3}\right)_{2}$ in the metathesis of linear olefins. J. Mol. Catal. A: Chem. 1999, 148, 97-103.

11. Warwel, S.; Brüse, F.; Demes, C.; Kunz, M.; Rüschgen Klaas M. Polymers and surfactants on the basis of renewable resources, Chemosphere 2001, 43, 39-48.

12. Ackman, R.G. Fundamental groups in the response of flame ionization detectors to oxygenated aliphatic hydrocarbons. J. G. Chromatogr. 1964, 173-179.

13. Marvey, B.B.; Du Plessis, J.A.K.; Vosloo, H.C.M.; Mol, J.C. Metathesis of unsaturated fatty acid esters derived from South African sunflower oil in the presence of a $3 \mathrm{wt} \% \mathrm{Re}_{2} \mathrm{O}_{7} / \mathrm{SiO}_{2}-$ $\mathrm{Al}_{2} \mathrm{O}_{3} / \mathrm{SnBu}_{4}$ catalyst, J. Mol. Catal. A:Chem. 2003, 201, 297-308. 
14. Reichardt, C. Solvatochromic dyes as solvent polarity indicators. Chem. Rev. 1994, 94, 2319-2358

15. Jordaan, M.; Vosloo, H.C.M. Ruthenium catalysts with a chelating pyridinyl-alcoholato ligand for application in linear alkene metathesis. Adv. Synth. Catal. 2007, 349, 184-192.

16. Coalter, J.N. III; Bollinger, J.C.; Eisenstein, O.; Caulton, K.G. R-groups reversal of isomer stability for $\mathrm{RuH}(\mathrm{X}) \mathrm{L}_{2}(\mathrm{CCHR})$ vs. $\mathrm{Ru}(\mathrm{X}) \mathrm{L}_{2}\left(\mathrm{CCH}_{2} \mathrm{R}\right)$ : access to four-coordinate ruthenium carbenes and carbines. New J. Chem. 2000, 24, 925-927.

17. Van Rensburg, W.J.; Steynberg, P.J.; Meyer, W.H.; Kirk, M.M.; Forman, G.S. DFT prediction and experimental observation of substrate-induced catalyst decomposition in Ruthenium-catalyzed olefin metathesis. J. Am. Chem. Soc. 2004, 126, 14332-14333.

18. Willock, D.J. Catalysis: Experimental and computational. Annu. Rep. Prog. Chem., Sect. B. 2005, $101,333-351$.

19. Adlhart, C.; Chen, P. Ligand rotation distinguishes first- and second-generation Ruthenium metathesis catalysts. Angew. Chem. Int. Ed. 2002, 41(23), 4484-4487.

20. Mol, J.C. Metathesis of functionalized acyclic olefins, J. Mol. Catal. 1991, 65, 145-162.

(C) 2008 by MDPI (http://www.mdpi.org). Reproduction is permitted for noncommercial purposes. 